\title{
Developing Good Governance through Strengthening Literacy Skills from Schools to Organizational Management: The Case of Indonesia
}

\begin{abstract}
Submitted 14/04/20, $1^{\text {st }}$ revision 09/05/20, $2^{\text {nd }}$ revision 15/06/20, accepted 30/07/20
\section{Abstract:}

$$
\text { Muhadam Labolo }{ }^{1 *} \text {, Sudarmono }{ }^{2} \text {, David } \text { Mayor }^{2}
$$

Purpose: The main issue in this study is the poor public organizational management in Indonesia due to the low quality of governance literacy skills among school graduates. Such a situation is caused by the weak and conventional public administration methods used by most public managers across the country, hence calling for improved approaches that can only be created through research.

Design/methodology/approach: In the present study, the authors have tried to establish a better way of teaching good governance by strengthening literacy skills at the school level. The current research applied an approach and development design, with the research respondents from selected local administration offices with varying characteristics from around Bandung city. It has been established that developing good governance through strengthening literacy skills among school graduates improves the management of the organization's competence, both public and private.

Findings: The model generated through this research is a learning model of literacy reading oriented to the development process and learning outcomes. Under the conditions of its final form, the model developed has some differences with other models that have been developed by experts in several previous studies.

Practical implications: The model gives a positive contribution to the improvement of the reading literacy skills of elementary school students.

Originality/Value: The proposed model is a solution to improve the students' habits and students' skills in reading comprehension in a variety of text types, either in scientific, social, and mathematical texts.
\end{abstract}

Keywords: Elementary education, entrepreneurship, financial literacy, student development.

JEL Code: G20, G23, N20.

Paper Type: Research study.

\footnotetext{
${ }^{1}$ Institut Pemerintahan Dalam Negeri, e-mail: muhadam@ipdn.ac.id

${ }^{2}$ Institut Pemerintahan Dalam Negeri (IPDN), Indonesia.
} 


\section{Introduction}

The twenty-first century is known as the information age (Bajwa, 2014). This labeling of the $21^{\text {st }}$ century as the information age is in line with the century's characteristics marked by the rapid development of information and global expansion. This development is supported by the development of communication technologies, especially in computing, which causes almost all social routines to become extemporaneous. In line with these characteristics, the demand for literacy skills is growing. According to Morocco et al (2008), humans' most important abilities are the ability to learn new things, including governance. Management literacy is characterized by four crucial points: the ability of high understanding, critical thinking skills, the ability to collaborate and communicate, as well as critical thinking skills.

In line with the development needs of literacy, the development of literacy skills of students in the school was even undergoing a paradigm shift. At least four competencies must be mastered by the students to play an active role in the twentyfirst century. The fourth student competencies that must be learned is the ability to read in high understanding, excellent writing skills to build and express meaning, the ability to speak accountably, and the ability to master a variety of influential digital media. As Concannon-Gibney and McCarthy (2012) stated, “...all students be provided with the problem-solving, communication and thinking skills that they will need to be effective workers and citizens in the 21st century. Reading plays a key role in science achievement." Associated with these conditions, it is not something unfair if the government ultimately changed the curriculum 2013 to the curriculum 2021.

Ministry of Education and Culture (Kemendikbud, 2013) explains that the development in curriculum 2013 is expected to produce productive, creative, innovative, and active citizen through strengthening attitude (know why), skills (know-how), and knowledge (know what) that are integrated to the lesson. This is reasonable efforts in line with the fact that numerous studies and surveys conducted by several international institutions always put Indonesia in the lowest order in the field of literacy even compared to some ASEAN countries.

The demands on the development of literacy education are reinforced by various measurement results on Indonesian students' multiliteracy skills that have been conducted by several international institutions that always puts Indonesia at the lowest order in the field of multiliteracy skills (science, math, and reading) even compared to some ASEAN countries. This is proven by the Progress in International Reading Literacy Study (PIRLS) survey conducted in 2011, Indonesian students still placed at lower order (the order of 42) compared to other countries studied (TIMSS and PIRLS, 2012). Multiliteracy assessment (reading literacy, scientific literacy, and mathematical literacy) conducted by the Programme for International Student Assessment (PISA) shows the same thing that Indonesia is a country with a low 
level of ability multiliteracy since 2000 to 2012 (the last period of measuring the data) (OECD, 2003; 2004; 2007; 2010; 2013).

Based on empirical data above, the efforts to improve the literacy learning process's quality should be made as early as possible so that the literacy competence of elementary school students can be increased. The exertion to improve the literacy skills of primary school students are also more crucial to be done in line with the implementation of Curriculum 2021, in which the content of Indonesian Language subject is integrated with other issues so that the learning is carried out through multiliteracy, integrated, and simultaneously differentiation approach. Through this approach, the students are expected to have much better competence of attitudes, skills, and knowledge. Through this approach, students are also likely to be more creative, innovative, and more productive. Hence, in the context of teaching literacy curriculum in 2021 is not only oriented to improve the cognitive abilities but more oriented towards the development of attitudes, skills, and knowledge of students.

Based on the above two conditions, efforts to improve the quality of teaching literacy should be made. The main steps that must be done are to formulate a learning model that corresponds to the demands of the 2021 curriculum, which is a teaching and learning model based on multiliteracy, integrative, and simultaneously differentiation learning. A learning model that thus expected to develop students' understanding through finding out and asking, develop the ability to collaborate and communicate through cooperative learning, and simultaneously improve the ability to think creatively in solving various problems through analytical thinking practice.

The effort of developing this model is a must since the existing variety of learning models today is not explicitly oriented towards the students' multiliteracy skills. In other words, the learning model which has been developed is only geared to specific literacy. The development of learning model based on multiliteracy, integrative, and differentiation is also in line with the opinion of Greenleaf et al. (2010) who states that "We must think strategically about the integration of literacy development across subject matter domains if we expect to develop students' multiple capacities." Furthermore, Greenleaf et al. (2010) reinforce the need to develop multiliteracy learning through the conclusions of their research, which stated that the integration of science literacy in the learning of science simultaneously could improve students' literacy.

Based on the description above, the researchers were interested in designing a Governance Managerial Literacy Model (GMLM). For that reason, this research focused on producing a good governance literacy model for the management of public offices, which is integrative and promotes managerial learning acquisition of leadership skills.

There are several goals in this study. The purpose of this study was to determine, explain and describe the final product learning model based multiliteracy, 
integrative, and differentiation concepts following the characteristics of elementary school students and the impact of the learning model based on multiliteracy, integrative, and differentiation concepts to increase students' literacy skills of primary school.

\section{Research Methods}

The method used in this study is mixed exploratory methods. This study was conducted in West Java Province. Data were obtained from three counties as objects of the study from around Bandung city. The qualitative research subjects were a unit and division directors and heads who had at least a degree working within the selected areas for the study. Based on this concept, the number of unit administrators and directors involved in the study were nine (9) people. The subject of research for the quantitative analysis was selected workers in the study counties who had attained at least a diploma or high school education. The subject of this research was determined by purposive sampling. The subject for the limited experiment was conducted in Antapani, Cimenyani, and Cibiru areas in Bandung city. At the same time, the subject of extensive experimental was conducted on employees from public offices from Bandung. The subject and object of the study were determined purposively with consideration of the location of the areas.

The instrument used to collect the data of this study were (1) semi-structured questionnaires, this is used to collect data of tracking needs (2) guidelines for semistructured interviews to collect unit and division heads response on the model (3) test to measure the literacy skills of workers, (4) assessment process shaped scoring rubrics to measure respondents activities, (5) the field notes to collect data of observation, (6) assessment guide for the learning process, and (7) documentation to collect data of research process. Based on the type of instrument used, this study resulted in two types of data, qualitative data, which are processed qualitatively, and quantitative data, which were prepared using a statistical method that is $(\mathrm{t})$ test and ANOVA test.

\section{Results and Discussion}

\subsection{A Design for Good Governance Literacy Model}

The model developed in this study is based on a standard design regarding good governance. The design was developed as a good governance managerial literacy model for organizational growth and development. A developed literacy model was based on the four fundamental theories used and then performed the process of model development. The process of developing this model is based on the systematic model development work initiated by Dick, Carey, and Carey (2009). The process of developing the model itself is done in four stages: (1) the stage of identification, (2) the design stage, (3) the development stage, and (4) the test phase of the experiment. 
The dissemination stage carried out the development process upon completing a whole series of model development and reporting of research.

Figure 1. Governance Managerial Literacy Model

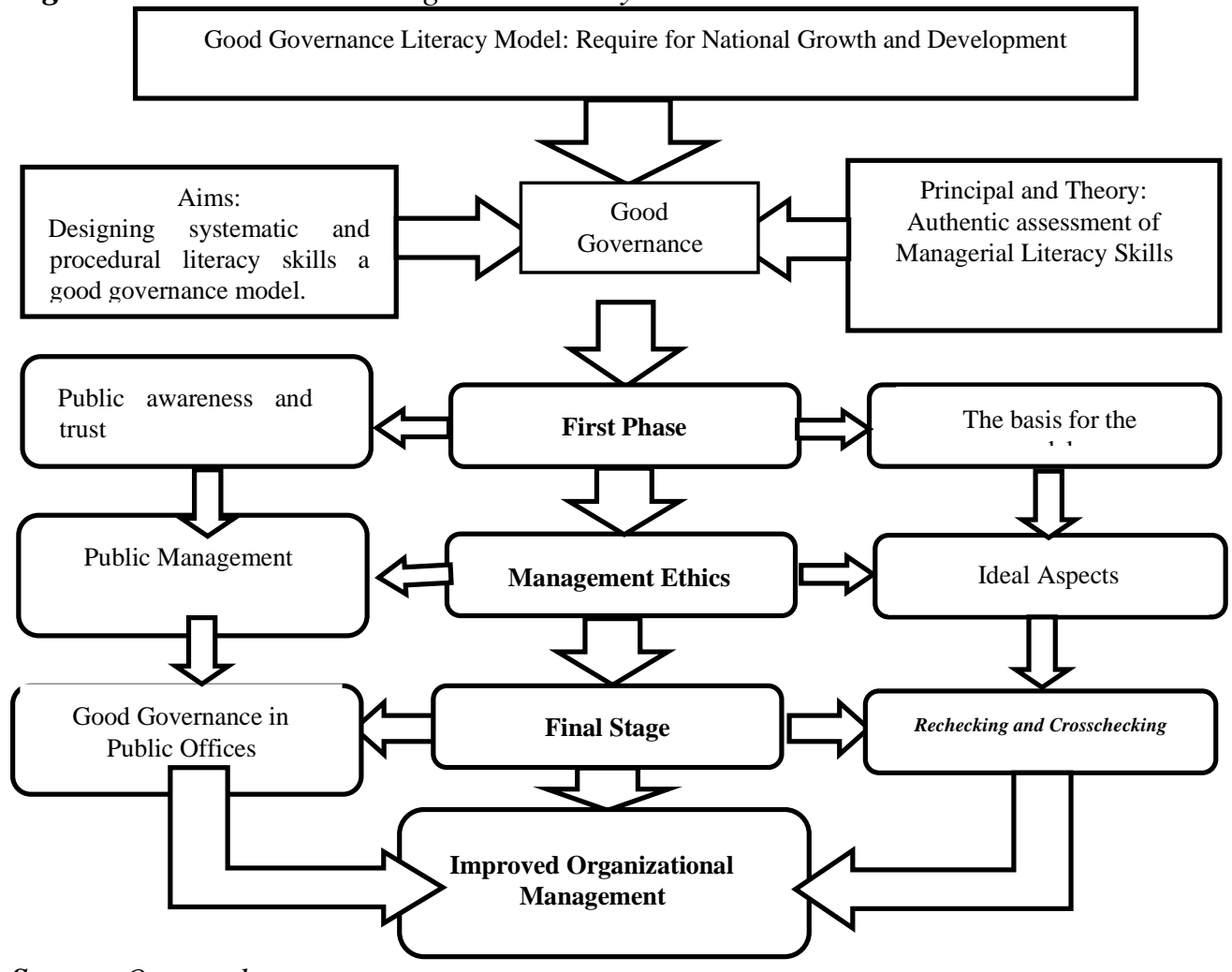

Source: Own study.

The final result of this development process is the concept of the Governance Managerial Literacy Model (GMLM) and its devices. The first tangible result is the theoretical basis of the GMLM facilitation process. In contrast, the second visible result is devices that can be used practically in implementing the model in the process of learning. Both of these outcomes is the final product that became the main product of this research.

\subsection{Managerial Literacy Enhancement Based on GMLM Model}

One of the components in organizational management is based on leadership skills. GMLM is a managerial cycle aimed at improving institutional governance. This cycle is a guide for implementing good governance in service delivery. In other words, this cycle depicts the stages of managerial literacy skills development through on the job training. This is usually known as managerial skills enhancement. 
Figure 2. Good Governance Literacy Model

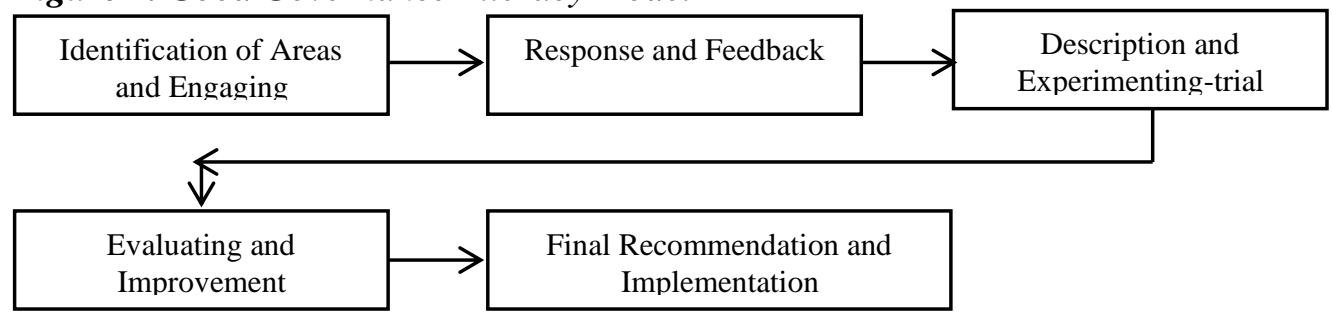

Source: Own study.

\subsection{Good Governance Literacy Model}

Based on Figure 2 above, managerial literacy development is a GMLM governance competence development model in stages comprising the following:

Identification of Areas and Engaging:

At this stage, teachers must engage students in learning through generating the schemata or prior knowledge that the students have. The next activity is that students are encouraged to link the topics to be discussed with the aim that students felt the most important topic to study. The third activity undertaken at this stage is under the guidance of the teacher students are expected to be able to make a variety of questions that are essential to be resolved through a type of critical inquiry work on the next stage. To prepare students to follow the following steps, teachers should also expose the students' learning activities that will be done as presenting the achievements of what activities students should produce at each stage of the learning activity.

Response and Feedback:

At this stage, the students will individually respond to all the challenges the teacher gave. Students actively started doing various investigations, observations, or simple research activities related to the question that has been made in the first phase. In this stage, students may use the library, schools' environment, or media that has been provided by the teachers to create a short answer to the question they made.

Description and Experimenting-trial:

At this stage, the students will elaborate more on the findings of individuals with friends in the group. As they perform elaboration activity, multiliteracy learning can be combined with cooperative learning of jigsaw. The process of elaboration should be to generate ideas together that can be used to answer questions that have been posted. The result of this elaboration activity outlined in the report that all members of the group should also possess the group.

Evaluating and Improvement:

At this stage, the group reviews the truth of the draft report. The review process can check the individual data, the validity of the source, and its accuracy. If the entire contents had been accurate, then the group appoint a representative to explain the work, and other students were prepared to write the note of class discussion, revising the results of the class input, and also the team tasked to maintain or take responsibility for the content of the report. 
Final Recommendation and Implementation:

At this stage, the group representative presents the results of their work to the class. The exposure continues with a discussion and ends with an overview activity, strengthening and developing the teacher's material.

\subsection{Good Governance Literacy Model, Reactions and Expectations}

\subsubsection{Model Implementation}

Implementation of the GMLM -based managerial Literacy Skills Model in the training process takes between 60-120 minutes, which was conducted in 2 sessions. For effective implementation, the training schedule was to be held four times a week. In the application, division heads and employees were required to express critical thinking, creative thinking, communication skills, passion, and motivation to work individually and in collaboration. During the application of the model, the unit and division heads were required to record the various activities and worker's performance indicators, organize and bind the habitual patterns of thinking and learning, and try to influence each other while at work.

\subsubsection{Reaction Principle}

The primary reaction that should be given is that the teacher must continuously raise the motivation to learn, develop critical, creative, and productive thinking skills, and make the students accustomed to working cooperatively, collaboratively, and communicatively. The reaction expected from the students is that students are ready to work hard, conscientious, diligent, and responsible for the learning process.

\subsubsection{Environmental Systems}

To implement this model, the expected environment available is the availability of the roots, which are arranged in relevant multidisciplinary science, media and learning resources, complete worksheets that process individuals and groups, and situations that support learning. It is equally important that students be aware of the actual role and duties during teaching and learning. This includes (1) optimizing the thinking skills, creative skills, and motivation to learn and work; (2) openness to ideas, concepts, thought and new input; (3) ready to work together collaboratively and cooperatively; and (4) the ability to optimize both intra and inter-group communication.

\subsubsection{Expected Impact}

GMLM- based model was developed with the hope of impacting instructional form of (1) improving the literacy skills of students, especially reading, (2) the development of students' skills in carrying out the process of scientific work during the teaching and learning process, and (3) improvement of students' skills in critical thinking, creativity, and innovative. The accompanying impact is in terms of (1) developing the character of students, including disciplines, meticulous, hard work, responsibility, tolerant, polite, courageous and critical as well as ethical and (2) forming life skills to the students, (3) improving the scientific attitude and (4) 
fostering students' ability to communicate, argue and collaborate/cooperate. Visually, the impact of the application of this model can be described as follows.

Figure 3. Impact of GMLM based Managerial Literacy model

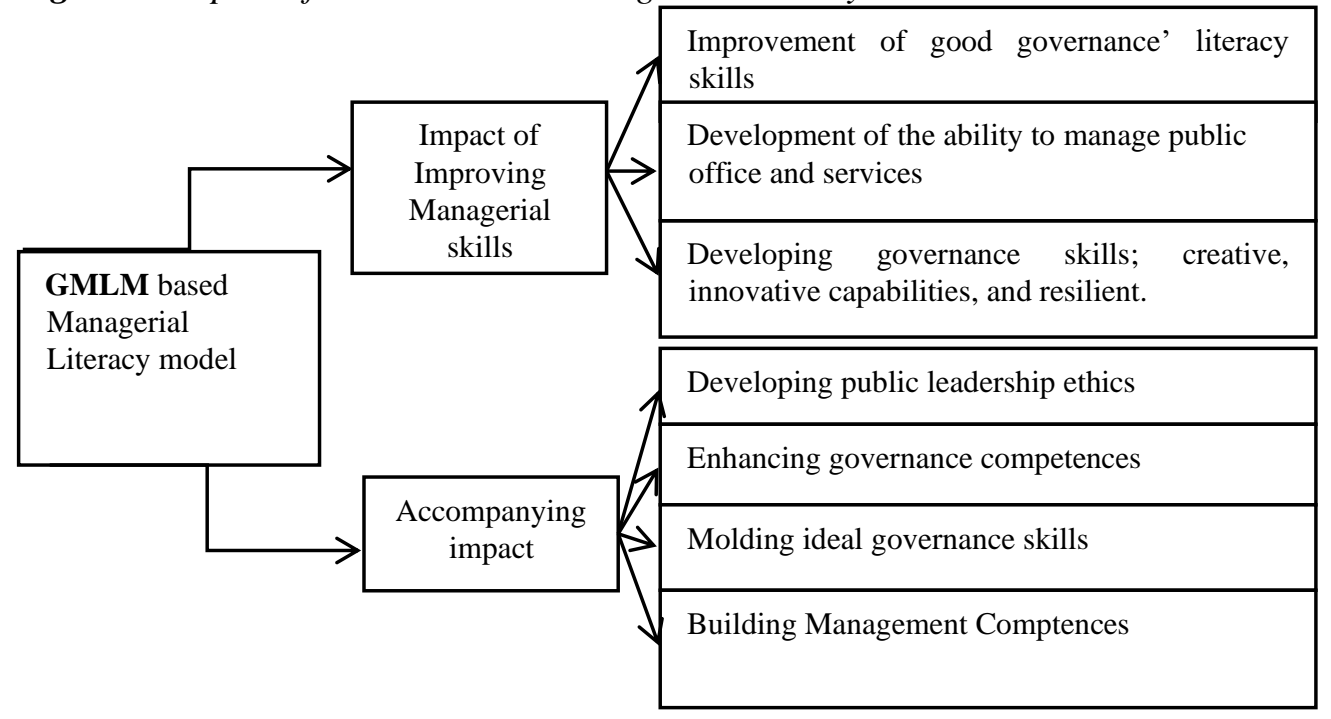

Source: Own study.

\subsection{Results}

Based on the test results of limited experiments that have been conducted three times, it shows that in experiments carried out reading literacy skills of students have increased significantly. A managerial literacy model based on good governance during the limited trial contributed substantially to improving students' reading literacy skills. This increase occurred in all phases of the research. Thus, the model developed can be used to enhance students' reading literacy in a limited scope.

Based on the test results of extensive experiments conducted in three experimental classes, it is noted that developed Teaching Literacy based on the GMLM model effectively developed students' reading literacy skills. On the other hand, it is also known that the conventional learning model of literacy also significantly contributed to the improvement of students' skills in reading comprehension. However, the traditional model used in the schools could only make significant differences in students' reading ability after it was applied three times. It was different from GMLM, which could significantly contribute to every process of training activities. To prove the effectiveness of this model, the t-test was then conducted.

Based on the findings, the GMLM Model developed deemed to have a higher level of effectiveness for increasing the reading literacy skills than the conventional model used in schools. This proves GMLM Model has effectively improved the managerial 
literacy skills of units and employees with at least a high school education certificate.

\subsection{Discussion}

\subsubsection{GMLM Model}

GMLM Model developed in this study is a literacy reading teaching and learning model that is oriented to the development of process and learning outcomes. In line with its objectives, the resulting models have essential functions and role in developing better teaching and learning activities, i.e., learning literacy reading which corresponds to the concept of appropriate interpretation, develop the habit to comprehend reading carefully and creatively, thus ultimately will give an impact on improving the literacy skills of students' reading.

This model requires teachers' work in total. This means the teachers should be whole-hearted in developing a harmonious, qualified, and dignified teaching and learning process. Through the application of the GMLM Model, the training process is built on awareness of roles shared between teachers and students. Collegiality, openness, and the knowledge system's developmental environment began to take shape through this application. This condition further encourages the creation of a conducive learning environment for the teaching and learning activity, starting with a positive attitude, both teachers and the students themselves. Then students have ultimately been accustomed to learning by starting their awareness of why and for what they are learning.

GMLM Model also deemed to be able to build more qualified teaching literacy reading. This is in line with the fact that this model requires the activities of teaching and learning literacy reading is always carried out by applying the appropriate syntax in every reading activities. Under these conditions, the second thing that developed in students' reading skills is physical and mental skills. So the students are accustomed to examining a discourse through scientific methods based on literacy exploring is automatic affects the students' intelligibility and survival understanding of the content of the discussion. Through such a teaching and learning process, students will gain the knowledge-based skills, so their acquisition of knowledge is more constructive and creative.

Moreover, the GMLM model has also been able to build formal learning. Dignified learning is the learning process based on an active effort based on the values of the characters. Through the GMLM model, cognitive knowledge formed was not based solely on students' intellectual abilities but also on the principles of cooperation, caring, honesty, perseverance, and other characters' values. Under these conditions, the intellectuality developed on students is also accompanied by the development of their personality. Based on this fact, the GMLM model was believed to form a superior person with reasonable intelligence and a noble character. 
Under the conditions of its final form, the developed GMLM model has some differences in the model developed through previous research. At least five significant differences between the models developed with a model that previously has been established. The first difference is that the GMLM Model developed through this research is prepared following the method of reading comprehension or learning model used. Based on the proper use of the model, the teaching and learning process is conducted in a more conducive environment and is directly able to improve the students' competence. This is in line with the opinion of Joyce et al. (2009), stating that the use of the learning model is believed to be able to improve the achievement of learning objectives.

The second difference is that the developed GMLM Model was devoted to the reading process so that the model was developed based on the students' real activity during reading. In line with the precise stages of this activity, the teacher can better monitor the students' learning difficulty level. The teaching and learning process using GMLM Model can expose its formative function during the learning process. This is in line with what Popham (2011) states that formative assessment is carried out during the learning process based on the students' real activity during learning. This way, this assessment will be able to provide feedback significantly to the improvement of learning achieved by the students.

The third difference is that the developed GMLM Model has been able to make students accustomed to possess characters during the learning process. Through the real activities conducted along with the learning model, students would unconsciously be accustomed to cultivate core values, and universal nature includes (1) honesty, (2) intelligence, (3) caring, and (4) firmness. The four characters' value is then explicitly developed the following authentic activities undertaken during the students' learning process.

Explicitly developed following oped GMLM Model does not only present the general activity in learning but also contains many activities oriented to the formation of better reading habits. The habit of reading in this study is not physical/visual reading habits but rather cognitive. The proposed habit of reading is the habit of the students in building knowledge-based on the material they read, including patterns to capture ideas accurately, process ideas appropriately and cooperatively, and acquired the habit of expressing ideas creatively and responsibly. Based on this fact, the developed GMLM Model emerged new ideas that reading habits are not only physical/visual but also mental/cognitive activities.

The fifth difference is that the developed GMLM Model comes with process worksheets that lead students to work based on the developed model's demands. Under these conditions, even if teachers do not master the model of teaching and learning reading well, teachers and students themselves will be able to implement and follow based on authentic learning activities aligned with the model. The use of process worksheets gives impacts on improving the ability of students directly and 
gradually along with the principle of learning stages as proposed by Axfor, Harders, and Wise (2009) which states that through the learning stages, pupils will have a set of skills, strategies, and sophisticated knowledge.

The successfully developed GMLM Model in teaching and learning reading literacy has also been directed to the acquisition of in-depth knowledge of what students read. This is in line with the activity and syntax form that continually emphasizes work-based brain activity that is important for comprehensive knowledge acquisition. Furthermore, various information or knowledge gained by the students also believed to last long since the experience instead learned through the real performance of the student than the instant acquisition of knowledge.

\subsubsection{The Contributions of GMLM Model Toward the Development of Reading Literacy Skills}

GMLM Model developed through this research also significantly give a positive contribution to the improvement of reading literacy skills of elementary school students. This increase occurred in all sample schools, which means that the GMLM model did not only function for high-level students but also low-level students. GMLM Model developed in this study is arranged through the activity of thinking. Along with this fact, the students are familiarized with the process discourse with appropriate strategies. With the approach they used, more students could explore the contents and context of discussion in-depth so that their understanding was increasing. The success in increasing the literacy reading skills through this activity is reciprocal with studies that have been conducted by Greenleaf et al. (2010) that develops reading apprenticeship learning model which also rely on the business as a stimulus for the development of students' skills in reading comprehension.

The purpose of teaching reading with optimizing authentic activity is to create literacy reading models based on students' learning activities. This has been a similar condition as research conducted by Greenleaf et al. (2010). Therefore, it is natural if GMLM Model in reading literacy learning developed in this study proved to improve students' reading comprehension. Other experts who develop teaching reading based on students' activities that relevant to the GMLM Model are Bryant et al. (2009), who concluded that the direct interaction of the student reading on pre, while, and post-reading stages will build students' knowledge about the material learned.

In connection with the preparation of worksheet as a form of authentic assessment process during the teaching reading process, GMLM Model developed in this study is consistent with the findings of research conducted by Alonzo et al. (2009) which concluded that the assessment would build a higher understanding in the pupils.

GMLM Model developed in the study is indeed able also to improve the quality of the learning process of reading literacy in schools. Because GMLM Model is a process to develop creativity, innovation, and productivity, this has been proving the 
contribution of the GMLM Model for teaching and learning literacy reading process. Through the implementation of this model, the teacher recognized that learning literacy reading becomes more exciting and creative so that students are challenged to be able to read the whole variety of reasonable discourse better either in science, social, or mathematical discourse.

\section{Conclusion}

GMLM Model generated through this research is a learning model of literacy reading oriented to the development process and learning outcomes. Under the conditions of its final form, the GMLM Model developed has some differences with other models that have been developed by experts in several previous studies. This difference indicates that GMLM Model developed has significant importance for the improvement of the quality of teaching and learning outcomes in reading literacy.

The survey results revealed that GMLM Model has proven to significantly contribute to the development of students' habits and increased students' reading literacy skills. This increase occurred in all sample schools, which means that GMLM Model has improved not only for high-level students but also for lower-level students. Given this reality, GMLM Model is indispensable to enhance the students' habits and students' skills in reading comprehension in a variety of text types either in scientific, social, and mathematical text.

\section{References:}

Alonzo, J., Basaraba, D., Tindal, G., Carriveau, R.S., 2009. They read, but how well do they understand? An empirical look at the nuances of measuring reading comprehension. Assessment for Effective Intervention, 35(1), 34-44.

Axford, B., Harders, P., Wise, F. 2009. Scaffolding Literacy: An integrated and sequential approach to teaching reading, spelling, and writing. Aust Council for Ed Research.

Bajwa, M. 2014. Emerging 21(st) Century Medical Technologies. Pakistan journal of medical sciences, 30(3), 649-655. https://doi.org/10.12669/pjms.303.5211.

Bryant, D.P. 2009. Instructional Strategies for Content-Area Reading Instruction. Intervention in School and Clinic, 34(5), 293-302.

Concannon-Gibney, T., McCarthy, M.J. 2012. The Explicit Teaching of Reading Comprehension in Science Class: a Pilot Professional Development Program. Improving Schools, 15(1), 73-88.

Dick, W., Carey, L., and Carey, J.O. 2009. The Systematic Design of Instruction. New Jersey, Pearson.

Greenleaf, C.L., Litman, C., Hanson, T.L., Rosen, R., Boscardin, C.K., Herman, J., Schneider, S.A., Madden, S., Jones, B. 2011. Integrating literacy and science in biology: Teaching and learning impacts of reading professional apprenticeship development. American Educational Research Journal, 48(3), 647-717.

Joyce, B. 2001. Models of Teaching. New York, Allyn, and Bacon.

Kemendikbud. 2013. Materi Pelatihan Guru Implementasi Kurikulum 2013. Jakarta, Kemendikbud.

Morocco, C.C. 2008. Supported Literacy for Adolescents: Transforming Teaching and 
Content Learning for The Twenty-First Century. San Francisco, Jossey-Bass A Wiley Imprint.

OECD. 2003. Literacy Skills for the World of Tomorrow: Further Results from PISA 2000. Canada, OECD.

OECD. 2004.Learning for Tomorrow's World: First Results from PISA 2003. Canada, OECD.

OECD. 2007. PISA 2006: Sciences Competencies for Tomorrow's World Volume 1 Analysis. Canada, OECD.

OECD. 2010. PISA 2009 Results: What Students Know and Can Do Volume I. Canada, OECD.

OECD. 2013. PISA 2012 Results: What Students Know and Can Do Volume I. Canada, OECD.

Popham, W.J. 2011. Transformative assessment in action: An inside look at applying the process. Alexandria, ASCD.

TIMSS and PIRLS. 2012. PIRLS 2011 International Results in Reading. Chestnut. 